\title{
Shear bond strength of various luting cements to fixed prosthodontic restorative materials
}

\author{
Simel Ayyildiz ${ }^{1}$, Faruk Emir ${ }^{1}$, Elif Pak Tunc ${ }^{2 *}$ and Deniz Sen ${ }^{2}$
}

*Correspondence:

epaktunc@istanbul.edu.tr

${ }^{2}$ Department

of Prosthodontics,

Faculty of Dentistry,

Istanbul University, Fatih,

34093 Istanbul, Turkey

Full list of author information

is available at the end of the

article

\begin{abstract}
The aim of this study was to evaluate the shear bond strength (SBS) of three different cements to zirconia and lithium disilicate ceramic surface after thermal cycling. Thirty zirconia ( $Z$ ) and thirty lithium disilicate (L) disk specimens were prepared in $8 \mathrm{~mm}$ in diameter and $3.4 \mathrm{~mm}$ in thickness from zirconia and lithium disilicate ceramic blocks. Each group was divided into three subgroups (n:10). The specimens from all groups were bonded with three different cements using transparent polyethylene tubes: $\mathrm{Zn}$ Phosphate cement (ZPC); self-adhesive resin cement (SARC); adhesive resin cement (ARS). The specimens were then subjected to thermal aging procedure for 1 week under $37^{\circ} \mathrm{C}$ water bath. Shear bond strength (SBS) was determined using a universal testing machine at a crosshead speed of $1 \mathrm{~mm} / \mathrm{min}$. The specimens were also examined both with a scanning electron microscope (SEM) and a stereomicroscope. Statistical analysis was performed with one-way ANOVA. Pair-wise statistical comparison was made with Tukey test. The overall significance level was set at $\alpha=0.05$. For the tested groups, the SBS values ranged from $0.29 \pm 0.03$ to $12.10 \pm 0.25 \mathrm{MPa}$. L-SARC group yielded the highest SBS value $(p<0.05)$ among the groups, while Z-ZPC group had the lowest $(p<0.05)$. Significantly higher SBS values were found for all the groups of lithium disilicate disk specimens $(L)$ when compared to those of zirconia disk specimens ( $Z$ ) $(p<0.05)$. Tukey's pairwise comparisons revealed that SBS values of SARC groups were significantly higher than those of the ARC and ZPC groups $(p<0.05)$. Mode of failure analysis results showed that, the modes of failures were mixed with adhesive debonding predominantly with minimal resin residues $(<10 \%)$ for SARC groups. However, the other groups showed adhesive failure predominantly. Within the limitation of this in vitro study, it was concluded that selfadhesive resin cement had the highest shear bond strength values when bonded to lithium disilicate and zirconia ceramic surface. However zinc-phosphate cement demonstrated significantly lower shear bond strength values for both ceramic groups.
\end{abstract}

Keywords: Zirconia ceramic, Lithium-disilicate ceramic, Shear bond strength, Zn-phosphate cement, Adhesive resin cement

\section{Background}

The popularity of all-ceramic restorations has increased in recent years. Ceramic inlays, onlays, veneers and complete crowns have gained more demands [1]. Today, they are being used extensively in both anterior and posterior tooth restorations because they

\section{垈 Springer}

(C) 2015 Ayyildiz et al. This article is distributed under the terms of the Creative Commons Attribution 4.0 International License (http://creativecommons.org/licenses/by/4.0/), which permits unrestricted use, distribution, and reproduction in any medium, provided you give appropriate credit to the original author(s) and the source, provide a link to the Creative Commons license, and indicate if changes were made. 
replicate natural tooth color, and exhibit long term color stability and wear resistance [2]. There are several types of dental ceramics currently used in dentistry [3] and the clinical success and the longevity of these dental prostheses can be affected by multiple factors including the luting cement and the cementation procedure [1].

The primary function of the cementation is to establish reliable retention and a durable seal of the space between the tooth and the restoration, and to provide adequate optical properties especially for tooth-colored ceramic. Depending on the chemical composition of the cementing agent and the type of pretreatment of both the tooth surface and the indirect restoration, adhesion may be obtained by a chemical or micromechanical retention, or both [4]. Ceramic prostheses can be cemented either by use of conventional or adhesive cementation. Conventional cementation with water-based cements relies on micromechanical retention but adhesive bonding utilizes chemical and micromechanical retention $[3,5]$.

The most commonly used water-based permanent luting agents are zinc-phosphate cement, glass-ionomer cement or resin-modified glass-ionomer cement. Zinc phosphate cement has served for decades as the universal cement for different applications in restorative dentistry. Despite its well documented disadvantages of high solubility, lack of adhesion, and absence of chemical bond to the substrate, it is the most commonly used water-based permanent luting agent, depending on the retention and resistance form of the tooth preparation and an adequate marginal fit [4].

Studies showed considerable failure rates related to loss of retention when using waterbased cements and clinical evidence supports the importance of adhesive cementation for the long-term success of all-ceramic restorations and prostheses [6-8]. However, various authors suggested the use of water-based cements for zirconia ceramic restorations because they stated that higher fracture toughness of $\mathrm{ZrO}_{2}$ decreased the risk of fracturing the all-ceramic crown and removal of excess phosphate cement was perceived as being easier than resin cements $[9,10]$. Although it is well known that the adhesive bonding to tooth structure increases the fracture strength of the porcelain $[4,11,12]$, recently the use of a new brand of zinc-phosphate cement with different shade options is recommended by the manufacturer for cementation of zirconia and lithium disilicate ceramic restorations [13].

The aim of this study was to determine the shear bond strengths of self-adhesive and adhesive resin cements and zinc phosphate cement to zirconia and lithium disilicate substructures. The null hypotheses formulated was that, there is no difference between the shear bond strengths of cements bonded to zirconia and lithium disilicate ceramic substructures.

\section{Methods}

\section{Specimen preparation}

Zirconia

Thirty zirconia disk specimens were cut from zirconia ceramic blocks (KaVo Everest BIO ZS-Blank; KaVo Dental GmbH, Biberach, Germany), cleaned, and sintered at $1530{ }^{\circ} \mathrm{C}$ for 120 min. (EVA 1700; Linn High Therm, Eschenfelden, Germany) to their final dimensions ( $8 \mathrm{~mm}$ in diameter and $3.4 \mathrm{~mm}$ in thickness). The zirconia specimens were polished with 600 grit rotating silicone carbide paper (LaboPol-5, Struers, Ballerup, 
Denmark) and were airborne-particle abraded with $50 \mu \mathrm{m} \mathrm{Al} \mathrm{O}_{3}$ at 2.5 bars of pressure (15 s) at a maximum distance of $10 \mathrm{~mm} 1 \mathrm{~h}$ before bonding. All specimens were ultrasonically cleaned (Ultra 3; Tecno-Gaz S.p.A., Parma, Italy) in 99 \% ethanol for 15 min.

\section{Lithium disilicate}

Thirty lithium disilicate disk specimens were cut from lithium disilicate ingots (IPS e.max CAD, Ivoclar Vivadent; Schaan, Liechtenstein) cleaned, and sintered at $1500{ }^{\circ} \mathrm{C}$ for $90 \mathrm{~min}$ to their final dimensions ( $8 \mathrm{~mm}$ in diameter and $3.4 \mathrm{~mm}$ in thickness). All disk specimens were $5 \%$ HF etched for 20 s (IPS Ceramic Etching Gel, Ivoclar Vivadent).

\section{Bonding procedures}

Each group was divided into three subgroups (n:10) (Table 1). Polyethylene tubes (PTFE; DuPont Corp., Wilmington, Del) an inner diameter of $4 \mathrm{~mm}$ and a height of $2 \mathrm{~mm}$ were used to bond the cements to the ceramic specimen surfaces. The tubes were placed onto the center of the test surface of the specimens. Three types of cements were applied according to the manufacturer's instructions: Zn-phosphate cement (ZPC) (Hoffmann Harmonic Shades; Hoffmann, Berlin, Germany); self-adhesive resin cement (SARC) (RelyX U200; 3 M ESPE, St. Paul, MN); adhesive resin cement (ARS) (C\&B; BISCO, Inc., Schaumburg, IL, USA).

The mixed cement was poured into the polyethylene tubes until it fills up and covered with a flat glass. The dual-cure resin cement specimens were then light cured for $20 \mathrm{~s}$ from two opposite sides with a quartz-tungsten halogen light-curing device (Hilux 200, Benlioglu, Ankara, Turkey) with an irradiance of $600 \mathrm{~mW} / \mathrm{cm}^{2}$ and further cured in a light-curing unit (Dentacolor XS; Heraeus-Kulzer, Wehrheim, Germany) for an additional $90 \mathrm{~s}$. All specimens were then stored in $37{ }^{\circ} \mathrm{C}$ water for $24 \mathrm{~h}$ in a dark room to ensure complete polymerization of the cements. After $24 \mathrm{~h}$, the specimens were subjected to thermal aging procedure (Xenotest $150 \mathrm{~S}+\mathrm{TC}$, Atlas, Germany) for 1 week under $37^{\circ} \mathrm{C}$ water bath [14].

Table 1 The materials used in this study

\begin{tabular}{|c|c|c|c|c|}
\hline \multirow[t]{2}{*}{ Specimen (n:10) } & \multicolumn{2}{|l|}{ Core material } & \multicolumn{2}{|l|}{ Cement } \\
\hline & Type & Manufacturer & Type & Manufacturer \\
\hline L-SARC & \multirow[t]{3}{*}{$\begin{array}{l}\text { Lithium disili- } \\
\text { cate }\end{array}$} & \multirow{3}{*}{$\begin{array}{l}\text { IPS Empress 2; *Ivoclar } \\
\text { Vivadent AG, Schaan, } \\
\text { Liechtenstein }\end{array}$} & $\begin{array}{l}\text { Self-adhesive } \\
\text { resin cement }\end{array}$ & $\begin{array}{l}\text { RelyX U200; 3M ESPE, St. } \\
\text { Paul, MN }\end{array}$ \\
\hline L-ARC & & & $\begin{array}{l}\text { Adhesive resin } \\
\text { cement }\end{array}$ & $\begin{array}{l}\text { C\&B; BISCO, Inc., Schaum- } \\
\text { burg, IL }\end{array}$ \\
\hline L-ZPC & & & $\begin{array}{l}\text { Zn-Phosphate } \\
\text { cement }\end{array}$ & $\begin{array}{l}\text { Hoffmann's Harmonic } \\
\text { Shades; Hoffmann, Berlin, } \\
\text { Germany }\end{array}$ \\
\hline Z-SARC & \multirow[t]{3}{*}{ Zirconia } & \multirow{3}{*}{$\begin{array}{l}\text { KaVo Everest BIO ZS- } \\
\text { Blank, KaVo Dental } \\
\text { GmbH, Biberach, } \\
\text { Germany }\end{array}$} & $\begin{array}{l}\text { Self-adhesive } \\
\text { dual-cure } \\
\text { resin cement }\end{array}$ & $\begin{array}{l}\text { RelyX U200; 3M ESPE, St. } \\
\text { Paul, MN }\end{array}$ \\
\hline Z-ARC & & & $\begin{array}{l}\text { Auto-polym- } \\
\text { erizing resin } \\
\text { cement }\end{array}$ & $\begin{array}{l}\text { C\&B; BISCO, Inc., Schaum- } \\
\text { burg, IL }\end{array}$ \\
\hline Z-ZPC & & & $\begin{array}{l}\text { Zn-Phosphate } \\
\text { cement }\end{array}$ & $\begin{array}{l}\text { Hoffmann's Harmonic } \\
\text { Shades; Hoffmann, Berlin, } \\
\text { Germany }\end{array}$ \\
\hline
\end{tabular}




\section{Shear bond strength testing}

Shear bond strength (SBS) was determined using a Instron universal testing machine (Shimadzu AG-IS, Shimadzu, Kyoto, Japan) at a crosshead speed of $1 \mathrm{~mm} / \mathrm{min}$. A knife edge chisel was used for loading (Fig. 1). The obtained load values $(\mathrm{N})$ were converted into the megapascals $(\mathrm{MPa})$ by dividing the failure load $(\mathrm{N})$ by the bonding area $\left(\mathrm{mm}^{2}\right)$ [15].

\section{Examination of the failure modes}

The fractured interfaces on the ceramic surfaces were examined with a stereomicroscope (Leica MZ9.5, Wetzlar, Germany) at 50-200× magnifications to determine the mode of failure. Randomly selected specimens from each group were examined with a scanning electron microscope (SEM) (JSM 7000F, JEOL, Japan) (Figs. 2, 3, 4, 5 and 6).

\section{Statistical analysis}

Obtained data from shear bond strength test were evaluated statistically. One-way analysis of variance (ANOVA) was performed using Tukey's pairwise comparison test. The overall significance level was set at $\alpha=0.05$. Minitab statistical software, version 13.0 for Windows (Minitab Ltd., United Kingdom) was used for the calculations.

\section{Results and discussions}

For the tested groups, the SBS values ranged from $0.29 \pm 0.03$ to $12.10 \pm 0.25 \mathrm{MPa}$. L-SARC group yielded the highest SBS value $(\mathrm{p}<0.05)$ among the groups, while Z-ZPC group had the lowest $(\mathrm{p}<0.05)$. Significantly higher SBS values $(\mathrm{MPa})$ were found for the L disk specimens (L-SARC: $12.10 \pm 0.25$, L-ARC: $8.11 \pm 0.46$, and L-ZPC: $0.71 \pm 0.05)(\mathrm{p}<0.05)$ when compared to those of the zirconia disk specimens (Z-SARC: $11.23 \pm 0.47$, Z-ARC: $3.73 \pm 0.46$, and Z-ZPC: $0.29 \pm 0.03$ ). Tukey's pairwise

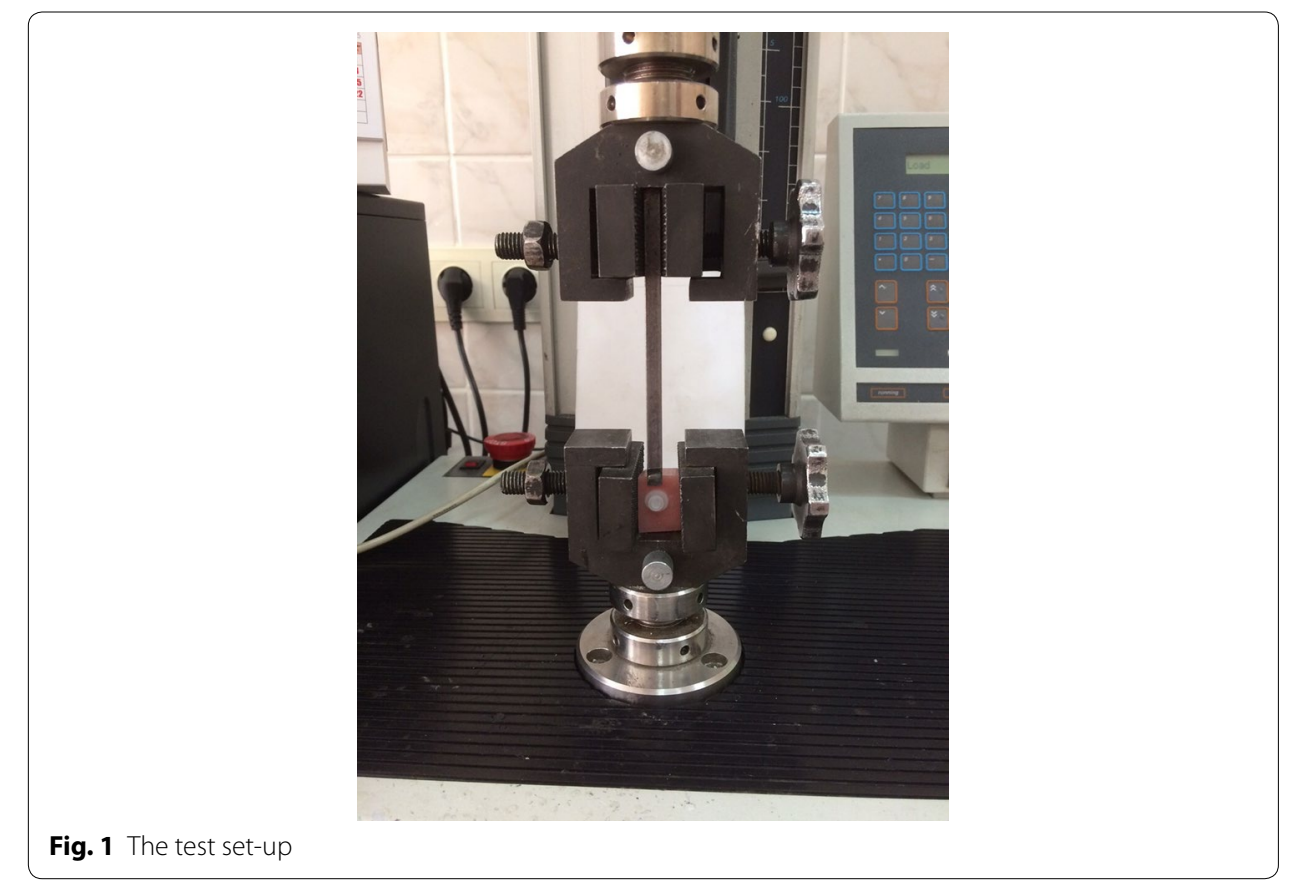




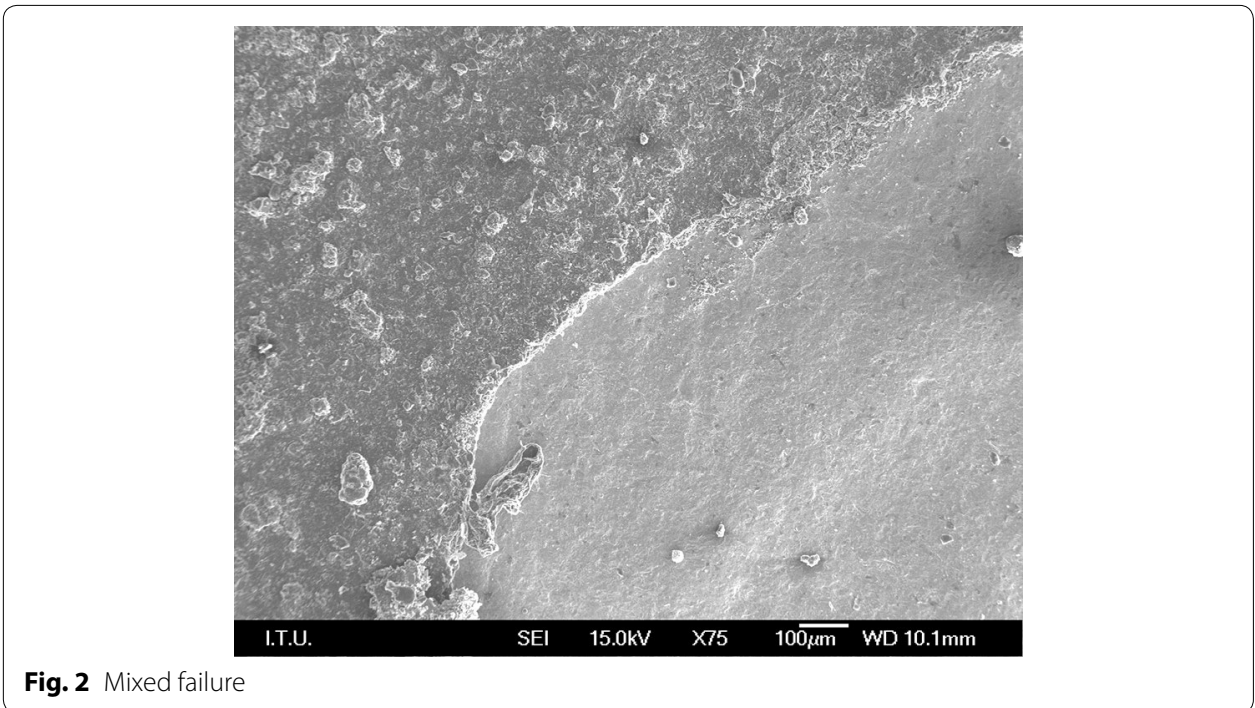

Fig. 2 Mixed failure

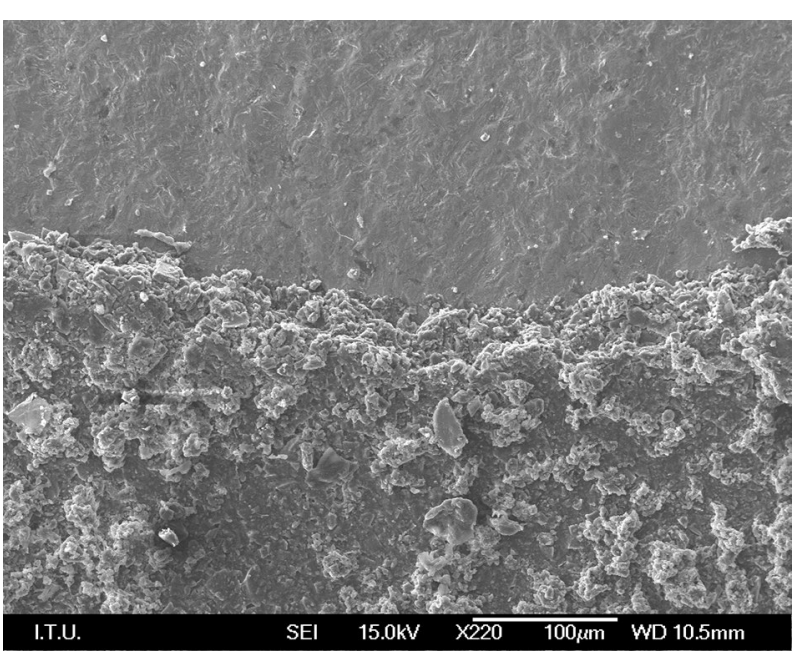

Fig. 3 Mixed failure (×220 magnification)

comparisons revealed that SBS values of SARC were significantly higher than those of the ARC and ZPC ( $\mathrm{p}<0.05)$ (Table 2; Fig. 1).

Mode of failure analysis results showed that the failures were mixed with adhesive debonding predominantly with minimal resin residues $(<10 \%)$ for the SARC groups (Figs. 2, 3). However, the other groups showed adhesive failure predominantly (Fig. 4). Representative specimens from $\mathrm{Z}$ and L groups (Figs. 5, 6) which were examined with SEM showed different surface textures depending on the different surface treatments.

According to the findings of this in vitro study, following results can be suggested: Cement type had a significant effect on the shear bond strength to lithium disilicate or zirconia substructures and the shear bond strength of an adhesive luting systems were higher than that of conventional cement, so the hypothesis was rejected.

When selecting a cement for all-ceramic restorations, the ability of strengthening the ceramic material is important. Adhesive bonding to tooth structure increases the 


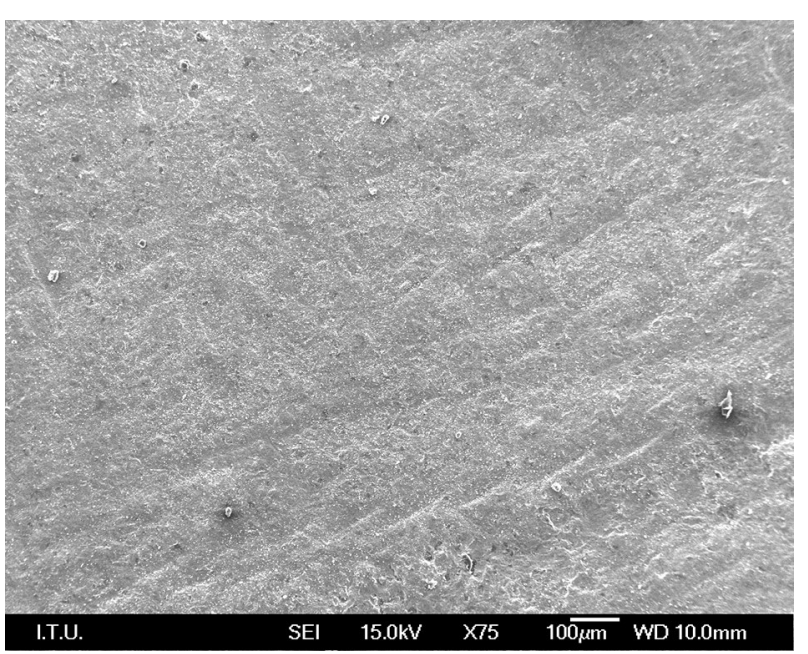

Fig. 4 Adhesive debonding

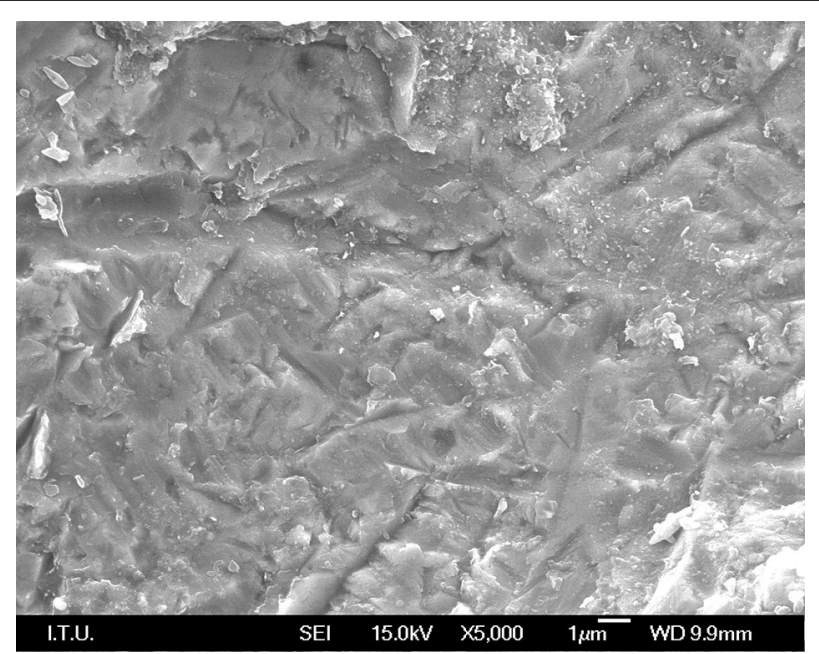

Fig. 5 SEM micrograph of modified zirconia surface after airborne-particle abrasion

fracture strength of the porcelain $[4,11,12]$. Heintze et al. demonstrated that leucite and lithium-disilicate crowns adhesively bonded with resin cement had higher fracture strength than those cemented with water-based cement [16] because, molecular adhesion in resin and hybrid cements is more effective than micromechanical retention which is the main mechanism for bonding of water-based cements to restorative materials. Although, conventional cements such as zinc polycarboxylate and glass ionomer cements have some limited adhesive properties, zinc phosphate cement exhibits only micromechanical interlocking [7]. Nevertheless as its use is not technique-sensitive, and it shows high physical strength, zinc-phosphate cement has been the most popular among all conventional cements [11, 17]. As a chemical bond with the zirconia surface can only be established with MDP containing resin cements [18] and the high fracture toughness of zirconia decreases the need of strengthening the ceramic by adhesive bonding, the use of zinc phosphate cement is recommended by various authors $[9,10]$. On the 


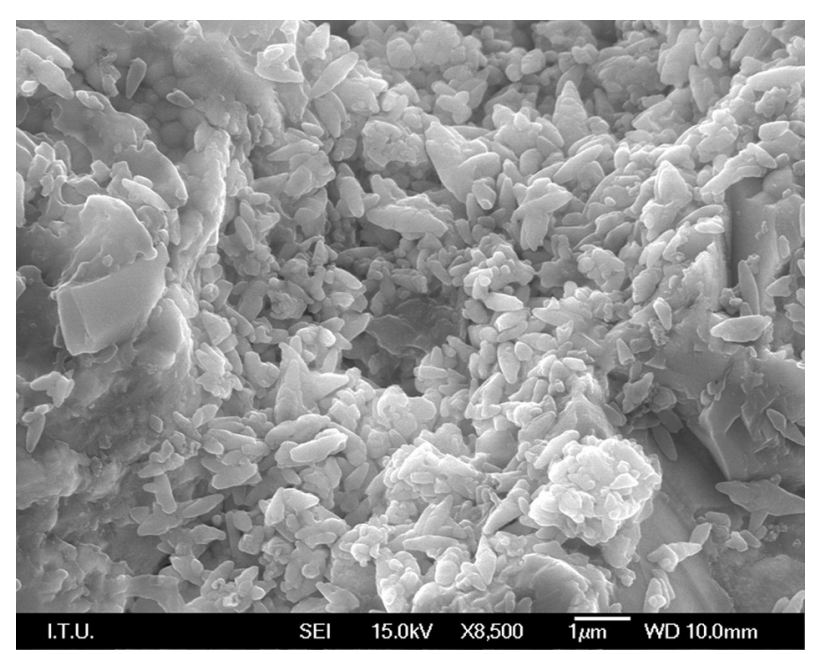

Fig. 6 SEM image demonstrating mature lithium disilicate crystals of IPS.e.max CAD ceramic after acid etching

Table 2 Shear bond strength mean values and standard deviations

\begin{tabular}{lcr}
\hline Samples & \multicolumn{2}{c}{ Shear bond strength $(\mathbf{M P a})$} \\
\cline { 2 - 3 } & Mean & SD \\
\hline L-SARC & $12.10^{*}$ & \pm 0.25 \\
L-ARC & $8.11^{*}$ & \pm 0.46 \\
L-ZPC & $0.71^{*}$ & \pm 0.05 \\
Z-SARC & $11.23^{*}$ & \pm 0.47 \\
Z-ARC & $3.73^{*}$ & \pm 0.46 \\
Z-ZPC & $0.29^{*}$ & \pm 0.03 \\
\hline${ }^{*} p<0.05$ & &
\end{tabular}

other hand, lithium-disilicate crowns need to be bonded adhesively with resin cement to have higher fracture strength [16]. However, recently the use of a new brand of zincphosphate cement with different shade options is recommended by the manufacturer for cementation of zirconia ceramic restorations and also lithium disilicate restorations. It is claimed by the manufacturer that this recently introduced zinc phosphate cement can be used for the final cementation of crowns and bridges made of oxide ceramics (zirconia and aluminium oxide) as well as lithium disilicate ceramics with a strength of more than $200 \mathrm{MPa}$ [13]. However it is stated by various investigators that water-based cements including zinc phosphate cement exhibited the lowest bond strength values when compared to resin cements $[4,11,12]$. Unfortunately, in comparison with resin cements tested in this study, the SBS value of L-ZPC group was significantly low $(\mathrm{p}<0.05)$ when compared to L-SARC and L-ARC groups. This result shows that the use of zinc-phosphate cement for cementing lithium-disilicate substructures may weaken the material and lead to fracture as no sufficient bonding is obtained [3].

The shear bond strength values of Z-ZPC group was also significantly low when compared to those of the Z-SARC and Z-ARC groups ( $<<0.05)$. However, oxide ceramics such as densely sintered pure alumina or partially stabilized zirconia exhibit significantly 
higher flexural strengths than those of lithium disilicate. Therefore, the influence of cementation mode on the strength of the restoration seems to be reduced [5].

This study revealed that, the zinc-phosphate cement groups revealed very low shear bond strength values among all groups. However, SBS value of L-ZPC group was significantly higher than that of Z-ZPC group $(\mathrm{p}<0.05)$. Also, significantly higher SBS values $(\mathrm{MPa})$ found for the $\mathrm{L}$ disk specimens when compared to the SBS values $(\mathrm{MPa})$ of the $\mathrm{Z}$ disk specimens for all cements $(\mathrm{p}<0.05)$. The pretreatment protocol used in this study involving sandblasting for zirconia and HF etching for lithium disilicate might be effective in advance of this result because; to enhance the bond strength of cementing agents, the ceramic surface can be conditioned by airborne-particle abrasion for highpurity oxide ceramics [19] and etched for lithium disilicate ceramics [20, 21]. Sandblasting increases the irregularity of the zirconium surface improving the interlocking with the cement (Fig. 5) [6]. However, ceramic surface etched with the hydrofluoric acid developes a micro-undercuts (Fig. 6) [22, 23]. It is considered that cement penetrates into these undercuts. Thus, the micro-undercuts mechanically retains the cement material, and high bond strengths are obtained when compared to airborne abrazed zirconia surface [2]. Also, the wetting behavior of the cement on the treated ceramic substrate might alter according to the material and surface treatment used [24, 25]. It may be concluded that the surface energy of the $L$ group increased more with the surface treatment when compared to $\mathrm{Z}$ group and this difference might lead statistically significant difference between groups.

For cementation to zirconia without separate primer application before luting, bonding efficacy depends entirely on the luting agent and its mechanical stability [24]. Regular bis-GMA resin cements which do not contain the MDP itself may show low bond strength values. However, RelyX U200 cement contains methacrylate monomers with phosphoric ester functional groups (MDP) and these functional monomers of RelyX U200 cement are able to form hydrogen bonds with zirconium oxide surfaces, enhancing adhesion and bond strength [26-28]. Significantly higher bond strength values between lithium disilicate ceramic and self adhesive resin cement was also stated. This was attributed to phosphoric-acid methacrylates in the self-adhesive resin cement, which provided a strong physical interaction, such as chemical reaction with the substructure [29]. Regarding the effect of cement type, in this study, the self-adhesive resin cement had significantly higher SBS values when compared to those of both adhesive resin cement and zinc phosphate cement.

In this study, the fractured interfaces on the ceramic surfaces were also examined with a stereomicroscope and SEM. Observed failure modes were classified. According to the classification, a cohesive failure was characterized by resin covering both test surfaces of a specimen. An adhesive failure showed complete debonding of the resin from one or both surfaces of a specimen. A specimen was considered to be a mixed failure when a portion of the test surfaces exposed and others had increments of retained resins. Results showed that for the SARC groups, which exhibited significantly higher bond strength values when compared to these of ZPC and ARC groups, the failures were mainly mixed with minimum resin retained on the surface of the ceramic (less than $10 \%)$. Scherrer et al. and Braga et al. claimed that if larger region of the fractured surface remains on one side or both, this result should be rejected from the data because it is 
not the indication of strong bonding but may be explained as the mechanics of the test and the brittleness of the material. They reported that only adhesive failures or mixed failures less than $10 \%$ should be considered for bond strength calculations [30, 31]. The results of this study were well-matched with these literatures.

\section{Conclusions}

Within the limitation of this in vitro study, it can be concluded that, although it is recommended by the manufacturer for cementation of zirconia and lithium disilicate ceramic restorations, zinc-phosphate cement demonstrated significantly lower shear bond strength values for both ceramic groups when compared to resin cements.

Authors' contributions

SA participated in the design of the study. FE carried out the specimen preparations and bond strength tests. EPT performed microscopic examinations. DS participated in the design and coordination of the study and obtained the test materials. All authors drafted the manuscript. All authors read and approved the final manuscript.

\section{Author details}

${ }^{1}$ Department of Prosthodontics, Center of Dental Sciences, Gulhane Military Medical Academy, Etlik, 06018 Ankara, Turkey. ${ }^{2}$ Department of Prosthodontics, Faculty of Dentistry, Istanbul University, Fatih, 34093 Istanbul, Turkey.

\section{Acknowledgements}

The authors thank to Prof. Dr. Ali Taylan Ula for performing the statistical analysis of this study.

\section{Competing interests}

The authors declare that they have no competing interests.

Received: 11 August 2015 Accepted: 6 October 2015

Published online: 14 October 2015

\section{References}

1. Kumbuloglu O, Lassila LV, User A, Toksavul S, Vallittu PK. Shear bond strength of composite resin cements to lithium disilicate ceramics. J Oral Rehabil. 2005;32:128-33.

2. Nagai T, Kawamoto Y, Kakehashi Y, Matsumura H. Adhesive bonding of a lithium disilicate ceramic material with resin-based luting agents. J Oral Rehabil. 2005;32:598-605.

3. Lawson NC, Burgess JO. Dental ceramics: a current review. Compend Contin Educ Dent. 2014;35:161-6.

4. Piwowarczyk A, Lauer HC, Sorensen JA. In vitro shear bond strength of cementing agents to fixed prosthodontic restorative materials. J Prosthet Dent. 2004;92:265-73.

5. Edelhoff D, Ozcan M. To what extent does the longevity of fixed dental prostheses depend on the function of the cement? Working Group 4 materials: cementation. Clin Oral Implants Res. 2007;18:193-204.

6. Román-Rodríguez JL, Fons-Font A, Amigó-Borrás V, Granell-Ruiz M, Busquets-Mataix D, Panadero RA, Solá-Ruiz MF. Bond strength of selected composite resin-cements to zirconium-oxide ceramic. Med Oral Patol Oral Cir Bucal. 2013;18:15-23.

7. Haddad MF, Rocha EP, Assunção WG. Cementation of prosthetic restorations: from conventional cementation to dental bonding concept. J Craniofac Surg. 2011;22:952-8.

8. Della Bona A, Shen C, Anusavice KJ. Work of adhesion of resin on treated lithia disilicate-based ceramic. Dent Mater. 2004;20:338-44.

9. Shahin R, Kern M. Effect of air-abrasion on the retention of zirconia ceramic crowns luted with different cements before and after artificial aging. Dent Mater. 2010;26:922-8.

10. Söderholm KJ, Mondragon E, Garcea I. Use of zinc phosphate cement as a luting agent for Denzir trade mark copings: an in vitro study. BMC Oral Health. 2003;7(3):1-11.

11. Jensen ME, Sheth JJ, Toiliver D. Etched-porcelain resin-bonded full-veneer crowns: in vitro fracture resistance. Compendium. 1989;10:336-47.

12. Ehlers V, Kampf G, Stender E, Willershausen B. Ernst CP Effect of thermocycling with or without 1 year of water storage on retentive strengths of luting cements for zirconia crowns. J Prosthet Dent. 2015;113:609-15.

13. Concise Product Knowledge; Hoffmann's Harmonic Shades; Hoffmann, Berlin, Germany.

14. Stawarczyk B, Hartmann R, Hartmann L, Roos M, Ozcan M, Sailer I, Hämmerle CH. The effect of dentin desensitizer on shear bond strength of conventional and self-adhesive resin luting cements after aging. Oper Dent. 2011;36:492-501.

15. Kadam A, Pujar M, Patil C. Evaluation of push-out bond strength of two fiber-reinforced composite posts systems using two luting cements in vitro. J Conserv Dent. 2013;16:444-8.

16. Heintze SD, Cavalleri A, Zellweger G. Fracture frequency of all-ceramic crowns during dynamic loading in a chewing simulator using different loading and luting protocols. Dent Mater. 2008;24:1352-61.

17. Sen D. Cementation. 1st ed. Istanbul: Quintessence Publishing; 2012. p. 7-15. 
18. Baldissara P, Querzè M, Monaco C, Scotti R, Fonseca RG. Efficacy of surface treatments on the bond strength of resin cements to two brands of zirconia ceramic. J Adhes Dent. 2013;15:259-67.

19. Awliya W, Oden A, Yaman P, Dennison JB, Razzoog ME. Shear bond strength of a resin cement to densely sintered high-purity alumina with various surface conditions. Acta Odontol Scand. 1998:56:9-13.

20. Thurmond JW, Barkmeier WW, Wilwerding TM. Effect of porcelain surface treatments on bond strengths of composite resin bonded to porcelain. J Prosthet Dent. 1994;72:355-9.

21. Stangel I, Nathanson D, Hsu CS. Shear strength of the composite bond to etched porcelain. J Dent Res. 1987;66:1460-5.

22. Jardel V, Degrange M, Picard B, Derrien G. Surface energy of etched ceramic. Int J Prosthodont. 1999;12:415-8.

23. Della Bona A, van Noort R. Shear vs. tensile bond strength of resin composite bonded to ceramic. J Dent Res. 1995;74:1591-6

24. Zorzin J, Belli R, Wagner A, Petschelt A, Lohbauer U. Self-adhesive resin cements: adhesive performance to indirect restorative ceramics. J Adhes Dent. 2014;16:541-6.

25. Noro A, Kaneko M, Murata I, Yoshinari M. Influence of surface topography and surface physicochemistry on wettability of zirconia (tetragonal zirconia polycrystal). J Biomed Mater Res B Appl Biomat. 2013;101:355-63.

26. Gerth HU, Dammaschke T, Zuchner H, Schafer E. Chemical analysis and bonding reaction of RelyX Unicem and Bifix composites: a comparative study. Dent Mater. 2006;22:934-41.

27. Blatz MB, Phark JH, Ozer F, Mante FK, Saleh N, Bergler M. In vitro comparative bond strength of contemporary self-adhesive resin cements to zirconium oxide ceramic with and without air-particle abrasion. Clin Oral Investig. 2010;14:187-92.

28. Mirmohammadi H, Aboushelib MN, Salameh Z, Feilzer AJ, Kleverlaan CJ. Innovations in bonding to zirconia based ceramics: part III. Phosphate monomer resin cements. Dent Mater. 2010;26:786-92.

29. Capa N, Ozkurt Z, Canpolat C, Kazazoglu E. Shear bond strength of luting agents to fixed prosthodontic restorative core materials. Aust Dent J. 2009;54:334-40.

30. Scherrer SS, Cesar PF, Swain MV. Direct comparison of the bond strength results of the different test methods: a critical literature review. Dent Mater. 2010;26:78-93.

31. Braga RR, Meira JB, Boaro LC, Xavier TA. Adhesion to tooth structure: a critical review of "macro" test methods. Dent Mater. 2010;26:38-49.

\section{Submit your manuscript to a SpringerOpen ${ }^{\circ}$ journal and benefit from:}

- Convenient online submission

- Rigorous peer review

- Immediate publication on acceptance

- Open access: articles freely available online

- High visibility within the field

- Retaining the copyright to your article

Submit your next manuscript at $\mathbf{s p r i n g e r o p e n . c o m ~}$ 